\title{
Fascial versus Fascio-cutaneous Pedicled Sural Flaps in the Reconstruction of Distal Leg, Ankle and Foot Soft Tissue Defects
}

\author{
Emmanuel P. Estrella ${ }^{1,2}$ and Ellen Y. Lee ${ }^{1,2}$ \\ ${ }^{1}$ Microsurgery Unit, Department of Orthopedics, College of Medicine and Philippine General Hospital, University of the Philippines Manila \\ ${ }^{2}$ ASTRO (Advanced STudy and Research in Orthopedics) Study Group, National Institutes of Health, University of the Philippines Manila
}

\begin{abstract}
Background. The coverage of soft tissue defects of the distal leg, ankle or foot poses several challenges to the reconstructive surgeon. Reconstructive procedures may range from simple skin grafting to complicated free tissue transfers. The reverse sural flap has been one of the most dependable methods for soft tissue coverage of such complex wounds. The purpose of this paper was to compare the clinical results of reverse sural flaps harvested with a fascial versus a fasciocutaneous pedicle.

Methods. A retrospective cohort of twenty-six patients who underwent a reverse sural flap procedure for complex wounds of the distal lower extremity was examined from January 1, 2003 to December 31, 2009, with a minimum follow-up of one month. Fifteen patients had a fascial pedicled flap, while eleven patients had fasciocutaneous pedicled flaps with a minimum of one month follow-up. The primary outcome was flap-related complications. Fisher's exact test was used to determine the differences between the two groups and the level of significance was set at $p \leq 0.05$.
\end{abstract}

Results. All flaps survived. Flap-related complications were more common in the fascial pedicled flap (6/15) compared with the fasciocutaneous pedicled flap (1/11). The difference was not significant $(p=0.09)$. In terms of cosmetic acceptability, 11 patients (11/15) in the fascial pedicle group and five patients (5/11) in the fasciocutaneous pedicle group expressed that the sural flap was acceptable.

Conclusion. Reverse sural flap was a reliable reconstructive procedure for coverage of soft tissue defects of the distal leg, ankle or foot. There was no significant difference in terms of complication rates for those with fascial compared with those with fasciocutaneous flaps. Cosmetic acceptability was higher for the fascial pedicled flap.

Key Words: soft tissue defect, sural flap, distal leg, pedicled flaps

Corresponding author: Emmanuel P. Estrella, MD

Microsurgery Unit, Department of Orthopedics

Philippine General Hospital

University of the Philippines Manila

Taft Avenue, Ermita, Manila 1000 Philippines

Telephone: +6325548466

Email: estee96@yahoo.com

\section{Introduction}

The use of the reverse sural flap has proved to be a reliable reconstructive procedure for coverage of soft tissue defects of the distal part of the leg, ankle and foot. The flap was initially popularized by Masquelet et al. ${ }^{1}$ Since then, many authors have used this flap to cover difficult wounds of the distal lower extremity. This unmodified version is typically an island fasciocutaneous flap with a fascial pedicle. Realistic complication rates of as much as $56 \%$ from two large studies ${ }^{2,3}$ have been reported. In a review article by Follmar et al., 133 complications in 722 flaps (18.5\%) were reported from the unmodified sural artery flap. Most of these complications were attributed to comorbid status, venous congestion and tunneling of the flap. ${ }^{2,3,5}$ In order to address these complications, especially those that involve problems with the venous drainage or tunneling of the flap, various modifications have been reported to protect the flap pedicle. Some of these modifications include having a "teardrop" skin over the pedicle, ${ }^{6}$ application of an external fixator for post-op care, " "supercharging" the flap by venous anastomosis to prevent congestion, ${ }^{8}$ delaying flap procedures, ${ }^{9,10}$ exteriorizing the pedicle to avoid tunneling, ${ }^{11}$ using a tissue expander if the pedicle is to be tunneled, ${ }^{12}$ inclusion of the peroneal artery in the flap ${ }^{13}$ or protecting the pedicle by including the skin over the pedicle during harvest. $9,14-17$

The tear-drop modification ${ }^{6}$ does not cover most of the pedicle and the application of an external fixator may be unacceptable for some patients. Delayed flap procedures may be a good alternative especially for those with comorbidities; however, a second procedure will be needed. The same is true for those using an exteriorized pedicle, where a second procedure will be needed to release the flap. "Super-charging" the flap ${ }^{8}$ entails microsurgical anastomosis, which may not be available in some institutions. The inclusion of the peroneal artery to ensure flap survival may entail tedious dissection and may be unnecessary. Perhaps the simplest method of modification is to use a fasciocutaneous pedicle instead of a fascial pedicle where the dermal and subdermal plexus will be preserved, which will decrease the chance of flap related necrosis. This technique will employ the inclusion of the skin over the pedicle as described in recent studies., ${ }^{9,14-17}$ In order to 
determine if the inclusion of the skin in the pedicle was effective in preventing flap-related complications compared with the conventional "island" flap with a fascial pedicle, we decided to compare the clinical results in terms of flaprelated complications of sural flap coverage with a fascial or fasciocutaneous pedicle. The purpose of this study was to compare the clinical outcome, specifically the complications, of reverse sural flaps done with a fascial pedicle versus those done with a fasciocutaneous pedicle.

\section{Methods}

A retrospective review of patients with small to midsized soft tissue defects of the distal leg, ankle or foot from January 2003 to December 2009 was done. Inclusion criteria for this study were coverage of small to midsized defects $\left(\leq 250 \mathrm{~cm}^{2}\right)$ of the distal leg, ankle or foot, using the reverse sural flap, with a minimum follow-up of one month. Exclusion criteria include a sural flap which was purely a fascial flap. A total of 26 patients were able to fulfill the criteria and were included in the study (Table 1). The sural flaps were classified into two groups: group 1 had a fasciocutaneous pedicled flap $(\mathrm{n}=11)$ and group 2 had a fascial pedicled flap $(n=15)$ (Figure 1).

Table 1. Demographic data of the two groups of patients

\begin{tabular}{|c|c|c|c|}
\hline & $\mathrm{p}$ Value & $\begin{array}{c}\text { Fascial } \\
\text { Pedicle, } \\
\text { n = 15 }\end{array}$ & $\begin{array}{c}\text { Fasciocutaneous } \\
\text { Pedicle, } \\
\text { n=11 }\end{array}$ \\
\hline Mean Age & 0.02 & 24.7 & 41.9 \\
\hline $\begin{array}{ll}\text { Sex } & \text { Male } \\
& \text { Female }\end{array}$ & & $\begin{array}{r}10 \\
5\end{array}$ & $\begin{array}{l}5 \\
6\end{array}$ \\
\hline Flap Size (cm2), SD & $\begin{array}{l}\mathrm{NS}^{* *} \\
\mathrm{NS}^{*}\end{array}$ & 80,43 & 101.64 \\
\hline Flap-related complications & $N S^{* *}$ & 5 & 1 \\
\hline Flap Acceptable & $N S^{* *}$ & 11 & 5 \\
\hline Mean follow-up (months) & $N S^{* *}$ & 19 & 13 \\
\hline Additional Procedures & $\mathrm{NS}^{* *}$ & 8 & 6 \\
\hline
\end{tabular}

There were 15 males and 11 females. The average age at the time of surgery was 32 years old (range, 7-68 years). The average follow-up period for the two groups was 16 months (range, 1-56 months). The soft tissue defects were secondary to trauma in 17 patients; five were from post soft tissue tumor resection, and four from chronic osteomyelitis of the distal tibia. The average size of the flap was $90 \mathrm{~cm}^{2}$ (range, $16-216 \mathrm{~cm}^{2}$ ). The average operative time was 2.5 hours (range, 1-3.5 hrs.). The choice on the type of flap was according to the surgeon's preference and the flap was usually performed by the rotating residents of the Hand Section. Flap-related complications were evaluated in terms of postoperative infection, flap necrosis or wound dehiscence. On final follow-up, ambulatory status (independent or with assistive device) and flap acceptability was evaluated in the out-patient clinics. Flap acceptability was evaluated by asking the patient whether the flap was "acceptable" or "not acceptable". The study was performed without blinding.

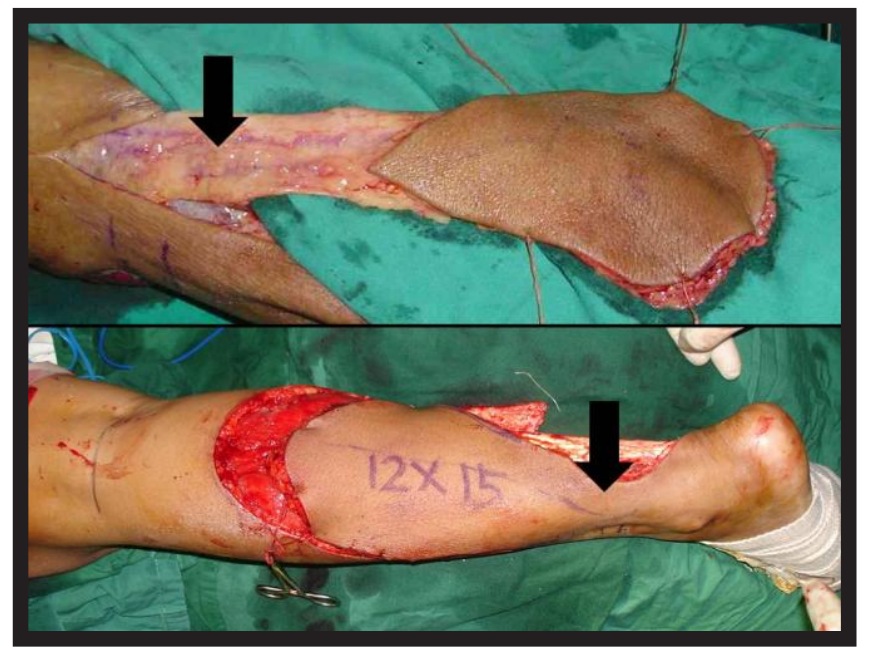

Figure 1. The flaps that were compared in this study were sural flaps with a fascial pedicle (arrow, upper picture) and with a fasciocutaneous pedicle (arrow, lower picture).

\section{Preoperative Evaluation}

None of the patients had an arteriogram to evaluate the peroneal perforators. In 19 patients, a portable Doppler was used to locate peroneal perforators in the distal fibula in order to assess the pivot point of the flap. These perforators range from 2-11 $\mathrm{cm}$ proximal to the tip of the lateral malleolus. In the remaining seven patients, the pivot point was at least $5 \mathrm{~cm}$ proximal to the tip of the lateral malleolus.

\section{Surgical Technique}

The surgical technique for harvesting the reverse sural artery flap has been well described in literature. ${ }^{1}$ All patients were in the prone position during wound debridement and flap coverage. Flap harvest was easier with the use of the tourniquet. The design of the flap was modified as needed to ensure that the lesser saphenous vein was in the middle of the flap and flap pedicle. A wide pedicle around $3-4 \mathrm{~cm}$ was employed to prevent vasospasm of the vascular pedicle during handling and insetting. None of the flaps were tunneled. All open injuries were covered with the sural flap once infection had been controlled as assessed by clinical evaluation. In patients with whom a tumor resection was performed, the sural flap coverage was performed during the same sitting. Additional procedures were performed 
either before the flap coverage (e.g., external fixator to stabilize the fracture dislocation or internal fixation for fracture fixation) or during the flap coverage (e.g., tendo Achilles reconstruction or repair).

Postoperatively, the leg was placed on a short leg posterior or anterior splint and elevated. The patient was either positioned prone or on the contralateral side with the operated limb elevated for two to three days. Bilateral crutch ambulation was usually started at 1.5-2 weeks after flap procedure, with progressive ankle motion exercises to prevent equinus deformity.

\section{Data Analysis}

Quantitative data (e.g., age, flap size, length of followup) were presented as means and standard deviations. Qualitative data (sex, flap-related complications, aesthetics) were presented as frequencies. Fisher's exact test for unequal variances was used to determine significant differences between the two groups. The outcome of interest was the development of flap-related complications. A p-value of $<0.05$ was considered significant.

\section{Results}

We had a total of 26 patients who had sural flap coverage. All 26 flaps survived. Four of the five patients who had wide resection of soft tissue sarcomas are alive and have had no recurrence on latest follow-up. In one patient with a clear cell sarcoma, the tumor recurred on the same leg. This was treated with a wide resection and a soleus flap to cover the anterior tibia. The four patients with osteomyelitis had stable flaps on recent follow-up. None of the patients developed infections after flap coverage. The tendo Achilles was repaired in two patients and reconstructed in three (Figure 2 and Figure 3). Six patients had lower extremity fractures which were managed accordingly. All patients were ambulant on recent follow-up; only two patients were using assistive devices (canes).

In terms of aesthetic acceptability, 11 patients (11/15) in the fascial pedicle group and five patients (5/11) in the fasciocutaneous pedicle group expressed that the flap was "acceptable". However, only one patient who said the flap was "not acceptable" had further debulking of the flap (fasciocutaneous group). Four months after the debulking, the patient was satisfied with the appearance of the flap.

\section{Complications}

There were seven flap-related complications in 26 patients: six patients in the fascial pedicle (40\%) group and one patient $(9.1 \%)$ in the fasciocutaneous pedicle group (Table 1). There was no significant difference in terms of complication rates between the fascial and fasciocutaneous pedicle groups using Fisher's exact test $(p=0.09)$. Three patients had limited ankle motion on follow-up, with two of them having radiographic evidence of tibio-talar arthritis. In

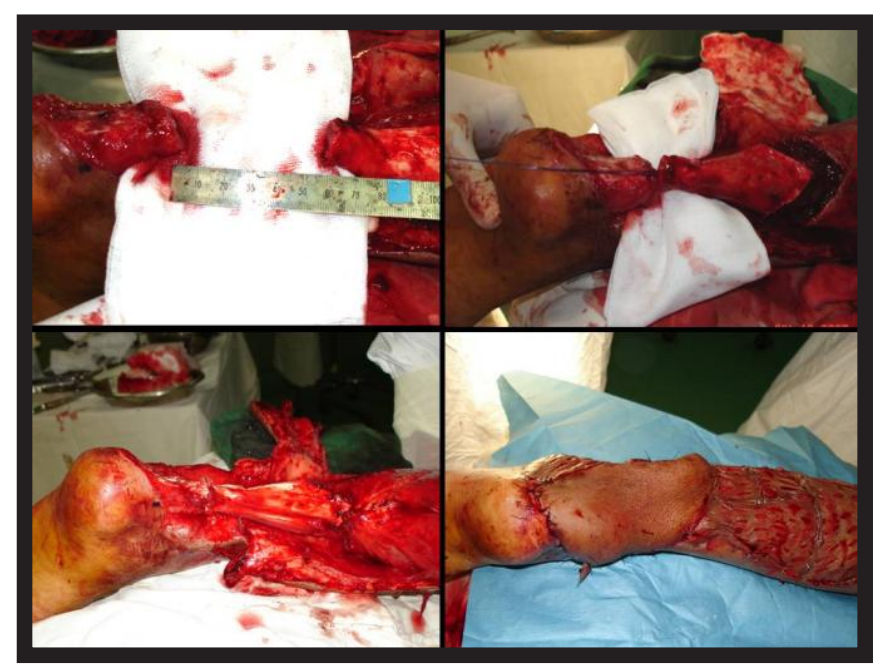

Figure 2. A 20-year-old male with an open transection of the tendo Achilles from a vehicular accident. A 6-cm tendo Achilles defect (upper left) was reconstructed with a V-Y advancement of the gastro-soleus complex (upper right and lower left). Sural flap coverage was used to cover the reconstruction (lower right).

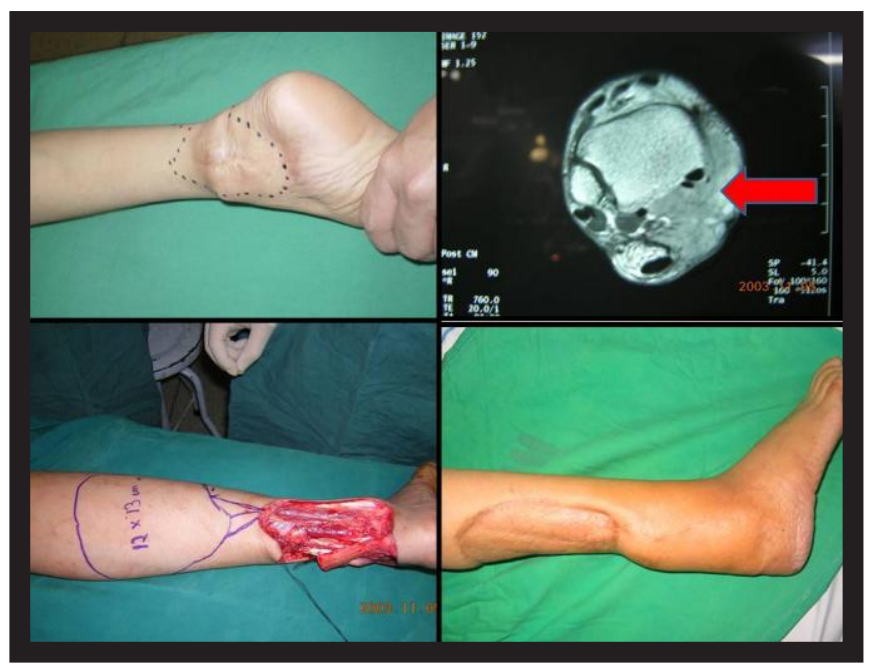

Figure 3. A 43-year-old female was referred for possible soft tissue coverage for wide excision of a recurrent soft tissue mass of the distal leg (upper left). On MRI, a large mass on the postero-medial aspect of the distal leg was evident (red arrow, upper right). After wide exicision, a 12 x $13 \mathrm{~cm}$ soft tissue defect on the posterior distal leg (lower left) was covered with a reverse sural flap (lower right). The tendo Achilles was repaired with primary suture. Histologic diagnosis was a fibrosarcoma.

those two patients, the tibio-talar arthritis was probably secondary to the initial injury (open ankle fracturedislocation). All flap-related complications were marginal necrosis of the flap tip (Figure 4). The tip necroses were 
treated non-operatively except in two cases where skin grafting was performed after debridement. Surgical debridement and skin grafting are usually performed if the necrosis is more than fifty percent of the flap or there is infection.

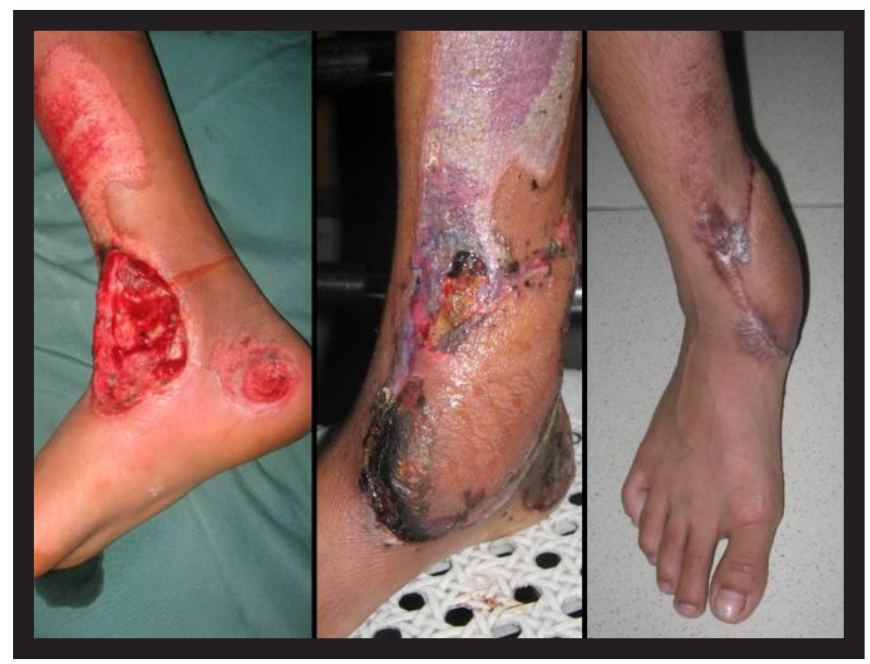

Figure 4. Marginal necrosis. This is an 11-year-old male who sustained an avulsion injury with an open ankle joint of the right leg (left). Three days after coverage of the wound with a fascial pedicled reverse sural flap, marginal necrosis of the flap tips were observed (middle). This was treated with daily dressing changes and good healing after 15 months of follow-up was achieved (right).

\section{Discussion}

The coverage of lower extremity defects poses several difficulties due to the paucity of soft tissues available for local flaps. The reverse sural flap has been suggested by some authors to be the first flap of choice for small to midsized defects of the distal leg, ankle or foot.9,17 The use of these pedicled flaps has made the coverage of such wounds simpler, making the operative time much shorter and thus resulting in a shorter hospital stay compared with free flaps. ${ }^{18}$ However, sural flaps are not without complications. The most common complication associated with the sural flap is venous congestion. In this case series, none had this complication. Several authors have modified the sural flap in order to avoid this complication.3,6,8,10-17,19 Most of these modifications were directed to address postoperative congestion. Such modifications include: performing a venous anastomosis, ${ }^{8}$ exteriorizing the pedicle to prevent compression and tunneling, ${ }^{11}$ use of tissue expander to stretch the skin of the tunnel ${ }^{12}$ and exteriorizing the lesser saphenous vein to allow continuous bleeding in cases of flap congestion. ${ }^{4}$ Other maneuvers were directed towards "protecting" the fascial pedicle by including the skin during flap harvest. ${ }^{14-17}$
A meta-analysis of 50 articles that used the unmodified distally based sural flap showed a total necrosis and flaprelated complication rate of $18 \%$ (partial and complete necroses). ${ }^{4}$ The modifications that were reviewed were using a purely fascial flap, inclusion of a cuff of muscle, and delaying the insetting of the flap. ${ }^{4,10}$ Such procedures may prove useful in cases where skin is not a problem but the underlying tissue needs fascial coverage (fascial flap), or when a large space needs to be filled up, such as in osteomyelitis (inclusion of the gastrocnemius in the sural flap) and in cases where the flap will have a high risk of necrosis such as those with co-morbidities (sural flap delay procedures).

In a recent risk analysis study on the complications of sural flaps, Parrett et al. ${ }^{20}$ noted that factors such as age over 70 years old, those with co-morbidities, and those with a body mass index of $>29$ have a greater likelihood of having flap-related complications. The authors identified smoking as the risk factor most independently associated with any sural flap procedure. Among the authors' suggestions were to delay the flap inset, especially in those patients with comorbidities. Although several authors have suggested the use of a fasciocutaneous pedicle for sural flap to decrease morbidity rate, none of these authors have compared sural flaps using a fascial or fasciocutaneous pedicle.

In this report, we compared two methods of sural flap harvest: a fascial and fasciocutaneous pedicle. The inclusion of the skin in the flap pedicle has been recommended by some authors to increase the chances of survival and avoid flap complications in reverse sural flap procedures in several small case series.9,15-17 Fascial pedicled sural flaps may lack the plexuses present with the inclusion of the skin and this may contribute to the occurrence of necrosis of the distal part of the flap. Also, additional venous drainage of the sural flap may be enhanced by inclusion of the subdermal venous plexus when the skin is harvested with the flap. Even though fascial pedicled flaps had a higher complication rate of $40 \%$ versus $9.1 \%$ in the fasciocutaneous pedicled flap, this was not statistically significant $(\mathrm{p}=0.09)$. Perhaps one reason for this is the small number of patients in both arms of the study. A larger sample might be able to detect significant differences between the two procedures. All flap-related complications were tip necroses which were managed conservatively with daily dressings. Only two patients required formal debridement and skin grafting. We found no correlation between flap size and the incidence of flaprelated complications $(p>0.05)$. For those patients where aesthetic acceptability may be a problem, the fascial pedicle flap may be used instead. In terms of aesthetics, since the aesthetic problem usually arises because of the bulkiness of the fasciocutaneous pedicled flap, especially at the pivot point, a secondary procedure may be performed to debulk the flap and release the fasciocutaneous pedicle. Among the major limitations of this study was the small number of 
participants from each group. A larger patient population with randomized allocation to the treatment group might more conclusively reveal the significance of the difference in terms of flap-related complications between the two techniques. If the sample size was adequate, a subgroup analysis taking into consideration the flap size, co-morbidity, whether a Doppler was used or not and perhaps the etiology might also be performed to achieve statistical difference. However, given the limited number of cases for this study, we found no significant difference in using fascial pedicled versus fasciocutaneous pedicled reverse sural flap in terms of flap-related complications. Our conclusion is limited to the small number of participants and the heterogeneity present in the population between the two groups. This should be taken into consideration and with caution.

\section{References}

1. Masquelet AC, Romana MC, Wolf G. Skin island flaps supplied by the vascular axis of the sensitive superficial nerves: anatomic study and clinical experience in the leg. Plast Reconstr Surg. 1992; 89(6):1115-21.

2. Almeida MF, da Costa PR, Okawa RY. Reverse-flow island sural flap. Plast Reconstr Surg. 2002; 109(2):583-91.

3. Baumeister SP, Spierer R, Erdman D, Sweis R, Levin LS, Germann GK. A realistic complication analysis of 70 sural artery flaps in a multimorbid patient group. Plast Reconstr Surg. 2003; 112(1):129-40.

4. Follmar K, Baccarani A, Baumeister SP, Levin LS, Erdmann D. The distally based sural flap. Plast Reconstr Surg. 2007; 119(6):138e-148e.

5. Yildrim S, Akan M, Aköz, T. Soft-tissue reconstruction of the foot with distally based neurocutaneous flaps in diabetic patients. Ann Plast Surg. 2002; 48(3):258-64.

6. Yilmaz M, Karatas O, Barutcu A. The distally based superficial sural artery island flap: clinical experiences and modifications. Plast Reconstr Surg. 1998; 102(7):2358-67.

7. Noack N, Hartmann B, Küntscher MV. Measures to prevent complications of distally based neurovascular sural flaps. Ann Plast Surg. 2006; 57(1):37-40.

8. Tan O, Atik B, Bekerecioglu M. Supercharged reverse-flow sural flap: A new modification increasing the reliability of the flap. Microsurgery. 2005; 25(1):36-43.

9. Kneser U, Bach AD, Polykandriotis E, Kopp J, Horch RE. Delayed reverse sural flap for staged reconstruction of the foot and lower leg. Plast Reconstr Surg. 2005; 116(7):1910-7.

10. Tosun Z, Ozkan A, Karacor Z, Savaci N. Delaying the reverse sural flap provides predictable results for complicated wounds in diabetic foot. Ann Plast Surg. 2005; 55(2):169-73.

11. Maffi TR, Knoetgen J 3rd, Turner NS, Moran SL. Enhanced survival using the distally based sural artery interpolation flap. Ann Plast Surg. 2005; 54(3):302-5.

12. Buluc L, Tosun B, Şen C, Sarlak AY. A modified technique for transposition of the reverse sural artery flap. Plast Reconstr Surg. 2006; 117(7):2488-92.

13. Yao SQ, Zhang FQ, Pan JS, Zhang YZ. Modified distally based sural nerve flaps in acute traumatic forefeet reconstructions. Ann Plast Surg. 2009; 63(1):77-80.

14. Afifi AM, Mahboub TA, Losee JE, Smith DM, Khalil HH. The reverse sural flap: modifications to improve efficacy in foot and ankle reconstruction. Ann Plast Surg. 2008; 61(4):430-6.

15. Dragu A, Bach AD, Kneser U, Horch RE. Two easy and simple modifications when using a distally based sural flap to reduce the risk of venous congestion. In Letters: Plast Reconstr Surg. 2008; 122(2):683-4.

16. Tu Yk, Ueng SW, Yeh WL, Wang KC. Reconstruction of ankle and heel defects by a modified wide-base reverse sural flap. J Trauma. 1999; $47(1): 82-8$.
17. Ayyappan T, Chadha A. Super sural neurofasciocutaneous flaps in acute, traumatic heel reconstructions. Plast Reconstr Surg. 2002; 109(7):2307-13.

18. Verhelle N, Vranckx J, Van den Hof B, Heymans O. Bone exposure in the leg: is a free muscle flap mandatory? Plast Reconstr Surg. 2005; 116(1):170-7; discussion 178-81.

19. Loonen MP, Kon M, Schuurman AH. Distally based sural flap modifications. Ann Plast Surg. 2010; 64(1):128.

20. Parrett BM, Pribaz JJ, Matros E, Przylecki W, Sampson CE, Orgill DP. Risk analysis for the reverse sural fasciocutaneous flap in distal leg reconstruction. Plast Reconstr Surg. 2009; 123(5):1499-504. 